\title{
可能性測度による区間回帰分析
}

\author{
田中 英 夫*，林 \\ 勲**, 長 坂 一 徳*
}

\section{INTERVAL REGRESSION ANALYSIS BY POSSIBILISTIC MEASURES}

Hideo TANaka, Isao Hayashi and Kazunori Nagasaka

\begin{abstract}
Since interval output data can be regarded as distributions of possibility, interval regression analysis is proposed by possibilistic interval systems. Interval data are given by fuzzy observation or expert knowledge and it becomes recently important to deal with interval data implying our partial ignorance on the phenomenon.

In our formulations, possibility and necessity measures, which are dual each other, are used to construct several formulations of interval regression models, depending on different situations under consideration. Our approach for obtaining a possibilistic interval model which fits to given interval output data can be reduced to LP problems. Thus, merits of our approach are to be able to obtain interval parameters by LP methods and to add expert knowledge on parameters in interval models to constraint conditions in LP problems. Some examples are depicted to illustrate these new techniques.
\end{abstract}

\section{1.はじめに}

通常, 回帰分析は確率モデルによって解析されてい る.与えられたデータと回帰分析によって得られた推 定值の差を観測誤差と見なし, 一般に観測誤差が正規 分布するといら仮定がなされている。しかし，回帰分 析の応用問題に扔いて，与兄られたデータに観測誤差 があると考党難いことが多い，与兄われたデータは現 実に生起しているのでデータはすべて現実に起こりう るものであると解釈できる。通常の回帰分析は確率モ デルに基づいているが，ここでは可能性モデル（田中 (1984)）で解积する新しい回帰分析手法を提案する。

われわれはファジィ数による線形回帰分析の定式化 をすでに行った（H. Tanaka, et al. (1982), 田中他 (1986), 林他 (1987), H. Tanaka, et al. (1987), H. Tanaka (1987))。ここでは, ファジィ数を区間に置き 換光るとともに，可能性，必然性測度 (D. Dubois \& H. Prade (1980)）を用いた定式化を行い，より理解しや すい新しい回帰分析手法を提案している。この手法は

* 大阪府立大学工学部 (College of Eng., University of Osaka Prefecture)

** 松下電器産業株式会社 (Mastushita Electric Industrial Co., Ltd.)
通常のデータのみならず区間出力データをも解析でき る、区間出力データはあいまいな観測機構または専門 家の知識として“だいたいこれぐらいの範囲”として 与えられる。

われわれが提案したファジィ回帰分析の応用はC. B. Zheng (1982), B. Heshmaty, et al. (1985) などに よって行われている。本論文では，区間概念を導入し て，区間線形システムを定義し，これをシステムモデ ルとした区間線形回㷌モデルを定式化し，通常のデー タと区間出力データを取扱う。区間概念を取扱らので, 可能性执よび必然性測度による包含関係の定義がなさ れ，区間出力データを取扱うときは 3 つの定式化がな されている，最後に，実際の例題に応用したときの結 果について述べ，われわれの手法が有効であることを 示す.

\section{2. 準備}

ここでは，定式化に必要な基本的概念を述べる。ま ず，区間線形システムを次のように定義する。

$$
\tilde{Y}=\tilde{A}_{1} x_{1}+\cdots+\tilde{A}_{n} x_{n}
$$

ただし， $x_{i}$ は入力であり区間係数 $\tilde{A_{i}}$ を $\tilde{A_{i}}=\left(\tilde{\alpha}_{i}, \tilde{C}_{i}\right)$ と表し， $\tilde{\alpha}_{i}$ は中心をまた $\tilde{c}_{i}$ 㤄を示している。この 
とさ区間出力 $\tilde{Y}$ は区間演算から

$$
\tilde{Y}=(\tilde{\boldsymbol{\alpha}} \boldsymbol{x}, \tilde{\boldsymbol{c}}|\boldsymbol{x}|)
$$

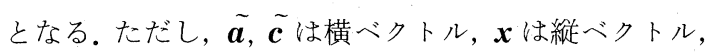
$|\boldsymbol{x}|=\left(\left|x_{1}\right|, \cdots,\left|x_{n}\right|\right)^{t}$ である. (2.2)の意味は区間係数 の可能性を考慮して区間出力が計算されていることを 示している。したがってこれは可能性線形システムと いえる。また区間の包含関係 $A_{i} \subset A_{j}$ は

$$
\tilde{\alpha}_{j}-\tilde{c}_{j} \leq \tilde{\alpha}_{i}-\tilde{c}_{i}, \tilde{\alpha}_{j}+\tilde{c}_{j} \geq \tilde{\alpha}_{i}+\tilde{c}_{i}
$$

と定義できる。

本論文で取扱ら $j$ 番目のデータは

$$
\left(Y_{j}, x_{j 1}, \cdots, x_{j n}\right)=\left(Y_{j}, \boldsymbol{x}_{j}\right) ; j=1, \cdots, m
$$

と表わす。ただし，区間出力 $Y_{j}$ は $Y_{j}=\left(y_{j}, e_{j}\right)$ で表わ し, 区間データでない通常の出力データのときは $e_{j}=$ 0 とする。データとして与光られる区間出力 $Y_{j}$ と, (2.1) から推定される区間推定 $\tilde{Y}_{j}$ との関係を可能性 測度および必然性測度で次のように定義する。

(i) 可能性: $\tilde{Y}_{j} \cap Y_{j} \neq \phi$ のとき, $Y_{j}$ の要素が $\tilde{Y}_{j}$ に属することは可能であることから可能性測度 $\operatorname{Pos}\left(\tilde{Y}_{j} \mid Y_{j}\right)$ は

$$
\operatorname{Pos}\left(\tilde{Y}_{j} \mid Y_{j}\right)= \begin{cases}1 ; & \tilde{Y}_{j} \cap Y_{j} \neq \phi \\ 0 ; \text { その他 }\end{cases}
$$

と定義される。

(ii) 必然性: $\tilde{Y}_{j}^{c} \cap Y_{j}=\phi$ のとき, $Y_{j}$ の要素が $\tilde{Y}_{j}$ に属することは必然であるので必然性測度 $\operatorname{Nes}\left(\tilde{Y}_{j} \mid\right.$ $\left.Y_{j}\right)$ は

$$
\operatorname{Nes}\left(\tilde{Y}_{j} \mid Y_{j}\right)= \begin{cases}1 ; & \tilde{Y}_{j}^{c} \cap Y_{j}=\phi \\ 0 ; & \text { その他 }\end{cases}
$$

と定義される。ただし， $\tilde{Y}_{j}^{c}$ は $\tilde{Y}_{j}$ の補集合であり， $\operatorname{Nes}\left(\tilde{Y}_{j} \mid Y_{j}\right)=1$ は $Y_{j} \subset \tilde{Y}$ を意味することに注意し よ5.

\section{3. 非区間デー夕に対する線形回帰分析}

入出力データが $\left(y_{j}, \boldsymbol{x}_{j}\right), j=1, \cdots, m$ として与兄ら れる場合を考兄る。線形モデルとして

$$
\tilde{Y}_{j}=\tilde{A}_{1} x_{j 1}+\cdots+\tilde{A}_{n} x_{j n}, \quad j=1, \cdots, m
$$

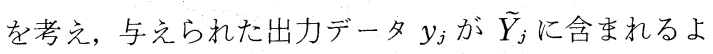
らに推定を行う。すなわち，すべての $j$ に対して $\operatorname{Nes}\left(\tilde{Y}_{j} \mid y_{j}\right)=1$ すなわち $\operatorname{Pos}\left(\tilde{Y}_{j} \mid y_{j}\right)=1$ となるよう にモデルを構成する。また推定区間 $\tilde{Y}_{j}$ の巾が小さい
㴗どよい推定であるので推定区間 $\tilde{Y}_{j}$ の巾の合計を最 小にする $\tilde{A_{1}}, \cdots, \tilde{A_{n}}$ を求める問題として定式化を行 う。すなわち, $y_{j} \in \tilde{Y}_{j}$ という拘束条件のもとに推定区 間 $\tilde{Y}_{j}$ の巾 $\tilde{\boldsymbol{c}}\left|\boldsymbol{x}_{j}\right|$ の合計を最小にする問題は次のよ うに定式化できる。

$$
\begin{aligned}
& \min \sum_{j} \tilde{\boldsymbol{c}}\left|\boldsymbol{x}_{j}\right|=\tilde{J}(\tilde{\boldsymbol{c}}) \\
& \boldsymbol{A}=(\tilde{\boldsymbol{\alpha}}, \tilde{\boldsymbol{c}}) \\
& y_{j} \geq \tilde{\boldsymbol{\alpha}} \boldsymbol{x}_{j}-\tilde{\boldsymbol{c}}\left|\boldsymbol{x}_{j}\right| \\
& y_{j} \leq \tilde{\boldsymbol{a}} \boldsymbol{x}_{j}+\tilde{\boldsymbol{c}}\left|\boldsymbol{x}_{j}\right| \\
& j=1, \cdots, m, \tilde{\boldsymbol{c}} \geq 0
\end{aligned}
$$

これはLP問題であるので容易に解くことができ る。李た専門家がある係数について漠然とした知識が あり，これを $B_{i}=\left(\tilde{\beta}_{i}, \tilde{d}_{i}\right)$ とすると， $A_{i} \subset B_{i}$ といら拘 束条件を導入できる。すなわち，

$$
\tilde{\beta}_{i}-\tilde{d}_{i} \leq \tilde{\alpha}_{i}-\tilde{c}_{i}, \tilde{\beta}_{i}+\tilde{d}_{i} \geq \tilde{\alpha}_{i}+\tilde{c}_{i}
$$

といら拘束条件を(3.2) につけ加光ることによって専 門家の漠然とした知識の中で最適な解を見つけること ができる，たと亲ば，係数が正であることが分かって いれば,この条件を導入して解を得ることがでさる。通 常の線形回帰では，しばしば説明変数の従属性のため にある係数が正に大きく表われ，それを補正するため にある他の係数が負として得られる。このとき, 得ら れた線形回帰モデルの解釈が困難になる。 区間線形回 帰モデルでは，拘束条件を専門家の知識から設定すれ ば，推定回帰モデルはもっと受容しやすいものになる であろう。

(3.2) の LP 問題の解の存在に対して次の定理がい 学る。

[定理 1]LP 問題 (3.2) の解は常に存在する.

（証明）与えられるデータ $\left(y_{j}, \boldsymbol{x}_{j}\right)$ は有限であるの で, $\boldsymbol{c}$ を十分大きくとれば(3.1)の LP 問題には許容集 合が存在するので解は常に存在する。

与兄られたデータ $\left(y_{i}, \boldsymbol{x}_{j}\right), j=1, \cdots, m$ はすべて現 実に可能であったものであるので, (3.1) の可能性モデ ルが用いられている。推定区間 $\tilde{Y}_{j}$ は可能性を表わし， 容易に分かるように次の定理が導ける。

[定理 2] LP 問題 (3.2) に批いてデータ数が増加 すれば， $\widetilde{J}(\tilde{\boldsymbol{c}})$ も増加する。

この定理は次のことを示している。データ数が増加 することはとれだけ多くの情報を得ており，したがっ 
て解析結果から得られる可能性は大きくなっている. このことは確率モデルによる線形回帰分析と大きく異 なる点であるが, 可能性モデルで解析しているので定 理 2 は当然の結果である。

以上の定式化から次のことがいえる。

（i） データ数が増加する注ど，区間推定の内が広 くなる、これは解析のためのデータが増加することは, それだけ情報が多くなり意志決定のための可能性が広 くなるからである。通常の回帰分析ではデータ数が増 加すればするほど区間推定が小さくなるのでこの性質 は対照的である。

（ii） 区間回帰分析では，出力と正の相関がある変 数に対する係数を正に限定して解くことができるとい う利点がある。一般的にい光ば, (3.3)のような専門家 の知識導入し，その中に限定して区間係数を推定で さる。この利点は定式化をLPに帰着させたことによ る.

（iii） 区間は，一般に我々の部分的無知を表わして いるといえるので, 解析結果にもこのような部分的無 知を反映させることができる。

(iv）与兄られたデータをすべて含むような区間線 形システムを得るので, 通常の回帰分析のよらな中心 傾向的な解釈でなく,すべてのデータが示す可能性だ けを示唆する。

\section{4. 区間出カデータに対する線形回帰分析}

ここでは区間出力データを $Y_{j}=\left(y_{j}, e_{j}\right)$ とし, $\boldsymbol{x}_{j}$ は 通常の入力データとする.このとさ2.で述べたように 可能性, 必然性測度を用いて図 1 のような 3 つの場合 が考兄れる。

(i) Nes 問題

区間線形システムを

$$
\bar{Y}_{j}=\bar{A}_{1} x_{j 1}+\cdots+\bar{A}_{n} x_{j n}
$$

とし, $\operatorname{Nes}\left(\bar{Y}_{j} \mid Y_{j}\right)=1, j=1, \cdots, m$ すなわち, すべて の $j$ に対して $\bar{Y}_{j} \supset Y_{j}$ の関係を満足し, 推定区間 $\bar{Y}_{j}$ の巾の合計を最小にする問題を考光る。これは次の LP 問題になる.

$$
\begin{aligned}
& \min \sum_{j} \overline{\boldsymbol{c}}\left|\boldsymbol{x}_{j}\right|=\bar{J}(\overline{\boldsymbol{c}}) \\
& \overline{\boldsymbol{A}}=(\overline{\boldsymbol{\alpha}}, \overline{\boldsymbol{c}}) \\
& y_{j}+e_{j} \leq \overline{\boldsymbol{\alpha}} \boldsymbol{x}_{j}+\overline{\boldsymbol{c}}\left|\boldsymbol{x}_{j}\right|, \\
& y_{j}-e_{j} \geq \overline{\boldsymbol{\alpha}} \boldsymbol{x}_{j}-\overline{\boldsymbol{c}}\left|\boldsymbol{x}_{j}\right|, \\
& j=1, \cdots, m, \overline{\boldsymbol{c}} \geq 0
\end{aligned}
$$

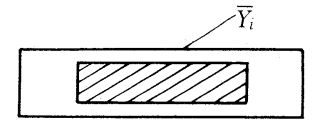

〔1〕Nes問題

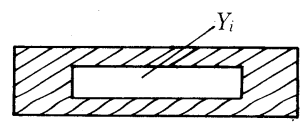

(2) C-Nes問題

図 13 つの定式化の説明

\section{(ii) C-Nes 問題}

区間線形システムを

$$
Y_{j}=\underline{A}_{1} x_{j 1}+\cdots+\underline{A}_{n} x_{j n}
$$

とし, $\operatorname{Nes}\left(\underline{Y}_{j}^{c} \mid Y_{j}^{c}\right)=1, j=1, \cdots, m$ すなわち $Y_{j} \subset Y_{j}$ の関係を満足し，推定区間 $Y_{j}$ の巾の合計を最大にす る問題を考光る。これは次の LP 問題になる。

$$
\begin{aligned}
& \max \sum_{j} \underline{\boldsymbol{c}}\left|\boldsymbol{x}_{j}\right|=\underline{J}(\underline{\boldsymbol{c}}) \\
& \underline{\boldsymbol{A}}=(\underline{\boldsymbol{\alpha}}, \underline{\boldsymbol{c}}) \\
& y_{j}+e_{j} \geq \underline{\boldsymbol{\alpha}} \boldsymbol{x}_{j}+\underline{\boldsymbol{c}}\left|\boldsymbol{x}_{j}\right|, \\
& y_{j}-e_{j}<\underline{\boldsymbol{\alpha}} \boldsymbol{x}_{j}-\underline{\boldsymbol{c}}\left|\boldsymbol{x}_{j}\right|, \\
& j=1, \cdots, m, \underline{\boldsymbol{c}} \geq 0 .
\end{aligned}
$$

(iii) Pos 問題

区間線形システムを

$$
\widehat{Y}_{j}=\widehat{A}_{1} x_{j 1}+\cdots+\widehat{A}_{n} x_{j n}
$$

とし, $\operatorname{Pos}\left(\hat{Y}_{j} \mid Y_{j}\right)=1, i=1, \cdots, m$ すなわち $\hat{Y}_{j} \cap Y_{j}$ キ $\phi$ とな関係を満足し，推定区間 $\widehat{Y}_{j}$ の巾の合計を 最小にする問題を考光る。こ扎は次の LP 問題になる。

$$
\begin{aligned}
& \min \sum_{j} \hat{\boldsymbol{c}}\left|\boldsymbol{x}_{j}\right|=\widehat{J}(\widehat{\boldsymbol{c}}) \\
& \widehat{\boldsymbol{A}}=(\hat{\boldsymbol{\alpha}}, \widehat{\boldsymbol{c}}) \\
& y_{j}+e_{j} \geq \widehat{\boldsymbol{\alpha}} \boldsymbol{x}_{j}-\widehat{\boldsymbol{c}}\left|\boldsymbol{x}_{j}\right|, \\
& y_{j}-e_{j} \leq \widehat{\boldsymbol{\alpha}} \boldsymbol{x}_{j}+\widehat{\boldsymbol{c}}\left|\boldsymbol{x}_{j}\right|, \\
& j=1, \cdots, m, \hat{\boldsymbol{c}} \geq 0 .
\end{aligned}
$$

さて，3つの定式化による区間データ解析の相互関 係について次の 2 つ場合に分けて述べる.

[I] 同定問題

ここでは与えられた区間データ $\left(Y_{j}^{0}, \boldsymbol{x}_{j}^{0}\right), j=1, \cdots$, $m$ が区間線形システム 


$$
Y_{j}^{0}=A_{1}^{0} x_{j}^{0}+\cdots+A_{n}^{0} x_{j n}^{0}
$$

を満足する場合を考党る。

[定理 3] 与えられたデータ $\left(Y_{j}^{0}, \boldsymbol{x}_{j}^{0}\right)$ が $(4.7)$ を満 足しているならば, Nes 問題, C-Nes 問題の解は次の ようになる。

$$
\boldsymbol{A}^{0}=\overline{\boldsymbol{A}}=\underline{\boldsymbol{A}}, \boldsymbol{Y}^{0}=\overline{\boldsymbol{Y}}=\underline{\boldsymbol{Y}}
$$

（証明） Nes 問題の場合だけを証明する。 $\left(Y_{j}^{0}, \boldsymbol{x}_{j}^{0}\right)$ が (4.7) を満足しているので, $Y_{j}^{0}=\left(y_{j}^{0}, e_{j}^{0}\right)$ に打ける $e_{j}^{0}$ は $e_{j}^{0}=\boldsymbol{c}^{0}\left|\boldsymbol{x}_{j}^{0}\right|$ となる。ゆ光に Nes 問題 (4.2) の拘 束条件は

$$
\begin{aligned}
& y_{j}^{0} \leq \bar{\alpha} x_{j}^{0}+\bar{c}\left|x_{j}^{0}\right|-c^{0}\left|x_{j}\right| \\
& y_{j}^{0} \geq \bar{\alpha} x_{j}^{0}-\bar{c}\left|x_{j}\right|+c^{0}\left|x_{j}\right|
\end{aligned}
$$

となり, $\bar{\alpha}=\alpha^{0}, \bar{c}=c^{0}$ と打くと $\left(\alpha^{0}, c^{0}\right)$ は許容解であ る。い方，

$$
\sum_{j} \boldsymbol{c}^{\prime}\left|\boldsymbol{x}_{j}^{0}\right|<\sum_{j} \boldsymbol{c}^{0}\left|\boldsymbol{x}_{j}^{0}\right|
$$

となる。舟在したと仮定すると，ある $i$ 対して $\boldsymbol{c}^{\prime}$ $\left|\boldsymbol{x}_{i}^{0}\right|<\boldsymbol{c}^{0}\left|\boldsymbol{x}_{i}^{0}\right|$ である。このとき(4.9)は

$$
\begin{aligned}
& y_{j}^{0} \leq \overline{\boldsymbol{\alpha}} \boldsymbol{x}_{i}^{0}-k_{i} \\
& y_{j}^{0} \geq \overline{\boldsymbol{\alpha}} \boldsymbol{x}_{i}^{0}+k_{i}
\end{aligned}
$$

となり，矛盾する。ただし， $k_{i}=\left(\boldsymbol{c}^{0}-\boldsymbol{c}^{\prime}\right)\left|\boldsymbol{x}_{i}^{0}\right|>0$ であ る。ゆえに $\overline{\boldsymbol{c}}=\boldsymbol{c}^{0}$ が最小解である。このとき，(4.9) は

$$
y_{j}^{0}=\bar{\alpha} \boldsymbol{x}_{j}^{0}
$$

となり $\bar{\alpha}=\alpha^{0}$ である.

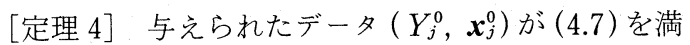
足しているならば, Pos 問題の $\widehat{J} は \widehat{J}(\widehat{\boldsymbol{c}})=0$ である. すなわち， $\hat{\boldsymbol{c}}=0$ である。

（証明） Pos 問題 (4.6) に扮いて， $\hat{\boldsymbol{c}}=0$ と抒けば拘 束条件は

$$
\begin{aligned}
& y_{j}^{0}+e_{j}^{0} \geq \widehat{\alpha} \boldsymbol{x}_{j} \\
& y_{j}-e_{j}^{0} \leq \widehat{\alpha} \boldsymbol{x}_{j}
\end{aligned}
$$

となり, $\hat{\boldsymbol{c}}=0$ は許容解である. $\hat{\alpha}=\boldsymbol{\alpha}^{0}$ も解の一つであ るが唯一ではない。

[定理 5] 与兄られたデータが通常のデータ $\left(y_{j}\right.$, $\left.\boldsymbol{x}_{j}\right)$ で通常の線形式 $y_{j}^{0}=\alpha^{0} \boldsymbol{x}_{j}$ を満足するならば,

$$
\begin{aligned}
& y_{j}=\bar{Y}_{j}=\underline{Y}_{j}=\hat{Y}_{j}, \alpha^{0}=\overline{\boldsymbol{A}}=\underline{\boldsymbol{A}}=\hat{\boldsymbol{A}} \\
& \bar{J}(\overline{\boldsymbol{c}})=\underline{J}(\underline{\boldsymbol{c}})=\hat{J}(\hat{\boldsymbol{c}})=0
\end{aligned}
$$

(証明) 3 つの定式化に扮いて $\boldsymbol{c}=0$ とおくことに よって $y_{j}=\boldsymbol{\alpha}^{0} \boldsymbol{x}_{j}^{0}$ となり (4.14) が得られる.

入出力データが区間線形システムを満足するなら ば，システム同定は Nes 問題または C-Nes 問題を解 くことによって得られる。また区間出力データが通常 のデータに退化した場合は 3 つの定式化は同じ問題に なっている。

\section{[II］区間データ解析問題}

一般に与兄られたデータは (4.7)を満足していない 場合が多い。このときデータ解析の観点から問題を考 光る。

[定理 6] Nes 問題 (4.2) およびPos 問題 (4.6)の 解は存在する。

(証明) Nes 問題 (4.2), Pos 問題 (4.6) そ打いて, $\boldsymbol{c}$ を十分大きな正数とすれば，与兄られたデータ（ $Y_{j}$, $\left.\boldsymbol{x}_{j}\right)$ に関係なく制約条件を満たすので，常に解は存在 する。一方, C-Nes 問題 (4.4) では $\underline{c}=0$ として子制約 条件を満たすとは限らないので, 解の保証はない。

[定理 7] C-Nes 問題の解が存在するための必要十 分条件は Pos 問題が $\hat{J}(\widehat{\boldsymbol{c}})=0$ となることである.

（証明） C-Nes 問題の解が存在すると仮定する。 こ のとき, Pos 問題に打いて $\overline{\boldsymbol{c}}=0$ とした制約領域が存 在することは (4.4), (4.6) から容易に分かる.したがっ て $\widehat{J}(\widehat{\boldsymbol{c}})=0$ である. 次に $\hat{J}(\widehat{\boldsymbol{c}})=0$ と仮定すると, C-Nes 問題の制約領域は $\underline{c} \geq 0$ として必ず存在する. ゆ光にC-Nes 問題の解は存在する。

[定理 8］もし C-Nes 問題に解が存在すれば,

$$
\bar{Y}_{j} \supset Y_{j} \supset \underline{Y}_{j}, j=1, \cdots, m
$$

が成り立つ。

（証明） $\bar{Y}_{j} \supset Y_{j} \supset \underline{Y}_{j}$ は Nes 問題掞よび C-Nes 問 題の構成から明らかである.

C-Nes 問題の解が存在しないときでも, Nes 問題と $\mathrm{Pos}$ 問題との解の関係について次の定理が成り立つ.

$$
\text { [定理 9] } \bar{J}(\overline{\boldsymbol{c}}) \geq \hat{J}(\widehat{\boldsymbol{c}})
$$

（証明）いま Nes 問題, Pos 問題の制約領域をそれ ぞれ $\bar{D}, \hat{D}$ とする。 (4.2), (4.6) の制約条件から

$$
\begin{aligned}
& y_{j}-e_{j} \leq y_{j}+e_{j} \leq \boldsymbol{\alpha} \boldsymbol{x}_{j}+\boldsymbol{c}\left|\boldsymbol{x}_{j}\right| \\
& y_{j}+e_{j} \geq y_{j}-e_{j} \geq \boldsymbol{\alpha} \boldsymbol{x}_{j}-\boldsymbol{c}\left|\boldsymbol{x}_{j}\right|
\end{aligned}
$$


となる。ゆえに Nes 問題の制約領域はP Pos 問題の制約

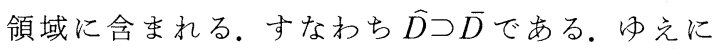
$\bar{J}(\overline{\boldsymbol{c}}) \geq \widehat{J}(\widehat{C})$ である.

最後に, 3 つの定式化の意味を様相論的に説明しょ 万. Nes問題において, Nes $\left(\bar{Y}_{i} \mid Y_{i}\right)=1$ は ${ }^{\forall} y_{j} \in Y_{j}$ に 対して $y_{j} \in \bar{Y}_{j}$ を意味している。すなわち $\operatorname{Nes}\left(\bar{Y}_{j} \mid\right.$ $\left.Y_{j}\right)=1 \Leftrightarrow \square\left(y_{j} \in Y_{j}\right)$ である.ただし $\square$ は必然性演算 子である。与えられた証拠 $y_{j} \in Y_{j}$ は必然的に推定区 間 $\bar{Y}_{j}$ に含まれる。同様にC-Nes 問題に打いて, Nes $\left(\underline{Y}_{j}^{c} \mid Y_{j}^{c}\right)=1$ は $\operatorname{Nes}\left(Y_{j} \mid \underline{Y}_{j}\right)=1$ を意味し, これは $y_{j}$ $\in \underline{Y}_{j}$ に対して $y_{j} \in Y_{j}$ である。すなわち, $\operatorname{Nes}\left(\underline{Y}_{j}^{c} \mid\right.$ $\left.Y_{j}^{c}\right)=1 \Leftrightarrow \square\left(y_{j} \in \underline{Y}_{j}\right)$ である. 推定区間 $\underline{Y}_{j}$ の要素 $y_{j}$ は必然的に証拠である区間出力 $Y_{j}$ に含まれている。 また Pos 問題において, $\operatorname{Pos}\left(\hat{Y}_{j} \mid Y_{j}\right)=1$ は $\left\{{ }^{\exists} y_{j} \mid y_{j} \in\right.$ $\left.Y_{i} \Leftrightarrow y_{i} \in \bar{Y}_{i}\right\}$ であることを意味している。すなわち $\operatorname{Pos}\left(\hat{Y}_{j} \mid Y_{j}\right)=1 \Leftrightarrow \triangleright\left(y_{j} \in Y_{j}\right)$ である.ただし〉は可能 性演算子である。推定区間 $\hat{Y}_{j}$ は与えられたデータか ら可能であることを意味している。

区間線形回㷌分析の定式化から次のことがい党る。

（i）もしデータが可能性線形システム (4.7)を満 足しているならば, 区間推定值は $\bar{Y}_{j}=Y_{j}$ となる.した がって次の指標

$$
g=\frac{\sum_{j} d\left(\underline{Y}_{j}\right)}{\sum_{j} d\left(\bar{Y}_{j}\right)}
$$

を導入する。ただし， $d\left(Y_{j}\right)$ は区間 $Y_{j}$ の巾を表わす。 $g=1$ ならば, 入出力データを完全に区間線形システム で表現でさているといえる。したがって $g$ が 1 に近い ほどよい推定区間線形システムである。

(ii) $g$ を指標として, 区間線形システムの説明変 数を変化させて, よりよい推定区間線形システムを得 ることができる。

(iii） $d\left(\underline{Y}_{j}\right) \leq d\left(\bar{Y}_{j}\right)$ であるので, $0 \leq g \leq 1$ である. ただし，C-Nes 問題の解が存在しないとさ $d\left(\underline{Y}_{j}\right)=0$ と定義している。

(iv) Pos 問題の解が $\hat{J}(\widehat{\boldsymbol{c}})=0$ となるように区間 線形システムを変化させることによって C-Nes 問題 の解を保証できる。

(v) このような区間分析は rough sets (Z. Pawlak (1982)) の解釈とょく一致している.

\section{5. 応用例}

ここでは通常のデータに対する区間回帰分析と区間 データに対する区間回帰分析との応用例を示す。

\section{1 住宅価格モデル}

プレハブ住宅 $\mathrm{A}$ 社のパンフレットから表 1 のデータ を得た。ここで，

入出データ： $x_{1}=$ 材質の良さ

$x_{2}=1$ 階床面積 $\left(m^{2}\right)$

$x_{3}=2$ 階床面積 $\left(\mathrm{m}^{2}\right)$

$x_{4}=$ 総室数

$x_{5}=$ 和室数

出力データ : $y=$ 住宅の評価価格(販売価格: 万円) ただし，材質は $1=$ 低級, $2=$ 中級, $3=$ 高級を示してい る.

区間線形モデルとして

$\tilde{Y}=\tilde{A_{0}}+\tilde{A_{1}} x_{1}+\tilde{A_{2}} x_{2}+\tilde{A_{3}} x_{3}+\tilde{A_{4}} x_{4}+\tilde{A_{5}} x_{5}$

とする. 係数は正であることを仮定し， $\alpha_{i} \geq 0, i=0, \cdots$, 5 という拘束条件の下に (3.2) の LP 問題の最適解を 求めた。このとき最適区間線形システムは

$\tilde{Y}=(245.167,37.634) x_{1}+(5.853,0) x_{2}+(4.786,0) x_{3}$

と得られた。このときの区間推定值を図 2 に示す。困 2 から, 価格の安いプレハブ住宅の販売価格は推定区 間の下端に位置し, 価格の高いものの販売価格は推定 区間の上端に位置している。これは高級品が付加価値 を含んで価格を高い目に設定しているといらわれれわ れの直観とよく合っていることを示している.

表 1. プレハブ住宅に関するデータ

\begin{tabular}{rc|rrccc}
\hline No. & $y_{i}$ & \multicolumn{1}{c|}{$x_{1}$} & \multicolumn{1}{c}{$x_{2}$} & $x_{3}$ & $x_{4}$ & $x_{5}$ \\
\hline 1 & 606 & 1 & 38.09 & 36.43 & 5 & 1 \\
2 & 710 & 1 & 62.10 & 26.50 & 6 & 1 \\
3 & 808 & 1 & 63.76 & 44.71 & 7 & 1 \\
4 & 826 & 1 & 74.52 & 38.09 & 8 & 1 \\
5 & 865 & 1 & 75.38 & 41.10 & 7 & 2 \\
6 & 852 & 2 & 52.99 & 26.49 & 4 & 2 \\
7 & 917 & 2 & 62.93 & 26.49 & 5 & 2 \\
8 & 1031 & 2 & 72.04 & 33.12 & 6 & 3 \\
9 & 1092 & 2 & 76.12 & 43.06 & 7 & 2 \\
10 & 1203 & 2 & 90.26 & 42.64 & 7 & 2 \\
11 & 1394 & 3 & 85.70 & 31.33 & 6 & 3 \\
12 & 1420 & 3 & 95.27 & 27.64 & 6 & 3 \\
13 & 1601 & 3 & 105.98 & 27.64 & 6 & 3 \\
14 & 1632 & 3 & 79.25 & 66.81 & 6 & 3 \\
15 & 1699 & 3 & 120.50 & 32.25 & 6 & 3 \\
\hline
\end{tabular}




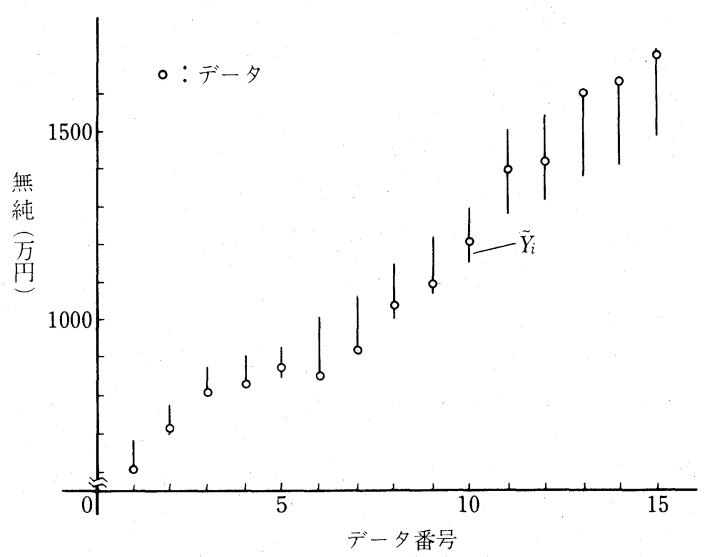

図 2 住宅価格モデルの結果

\section{2 砥削加工における送りと表面あらさとの関係}

ここで取扱ら研削の条件は次の通りである。

$\begin{array}{lll}\text { 砥石周速 } & 1250 \mathrm{~mm} / \mathrm{min} \\ \text { 切込 } & 0.105 \mathrm{~mm} \\ \text { 被削材 } & \mathrm{S}_{\mathrm{i} 3} \mathrm{~N}_{4} & \\ \text { 砥石 } & \text { 粒度 } & 170 \\ & \text { 集中度 } & 125\end{array}$

実験は送りを $10,15 ， 20 ， 25 ， 30 ， 35 ， 40 ， 45 ， 50$ $(\mathrm{mm} / \mathrm{min})$ としときの, 表面あらさを測定している。 表面あらさのデータは各送りに対し 3 回の加工実験を 行い，観測データを得た，各送りに対する表面あらさ の最大值と最小值から表 2 の区間出力データを得た. 区間線形システムとして,

$$
Y=A_{0}+A_{1} x+A_{2} x^{2}
$$

表 2 送り速度と表面あらさ

\begin{tabular}{c|c|c|c|c}
\hline \multirow{2}{*}{ No. } & $\begin{array}{c}\text { 送り } x \\
(10 \mathrm{~mm} / \mathrm{min})\end{array}$ & \multicolumn{2}{|c|}{ あらさ $(\boldsymbol{\mu}) y_{i}$} & あらさ $(\boldsymbol{\mu}) Y_{i}$ \\
\cline { 3 - 5 } & & 最小值 & 最大值 & $\left(y_{i}, e_{i}\right)$ \\
\hline 1 & 1.0 & 0.19 & 0.29 & $(0.240,0.050)$ \\
2 & 1.5 & 0.24 & 0.32 & $(0.280,0.040)$ \\
3 & 2.0 & 0.20 & 0.27 & $(0.235,0.035)$ \\
4 & 2.5 & 0.20 & 0.46 & $(0.330,0.130)$ \\
5 & 3.0 & 0.22 & 0.38 & $(0.300,0.080)$ \\
6 & 3.5 & 0.22 & 0.33 & $(0.275,0.055)$ \\
7 & 4.0 & 0.35 & 0.56 & $(0.455,0.105)$ \\
8 & 4.5 & 0.37 & 0.60 & $(0.485,0.115)$ \\
9 & 5.0 & 0.41 & 0.89 & $(0.650,0.240)$ \\
\hline
\end{tabular}
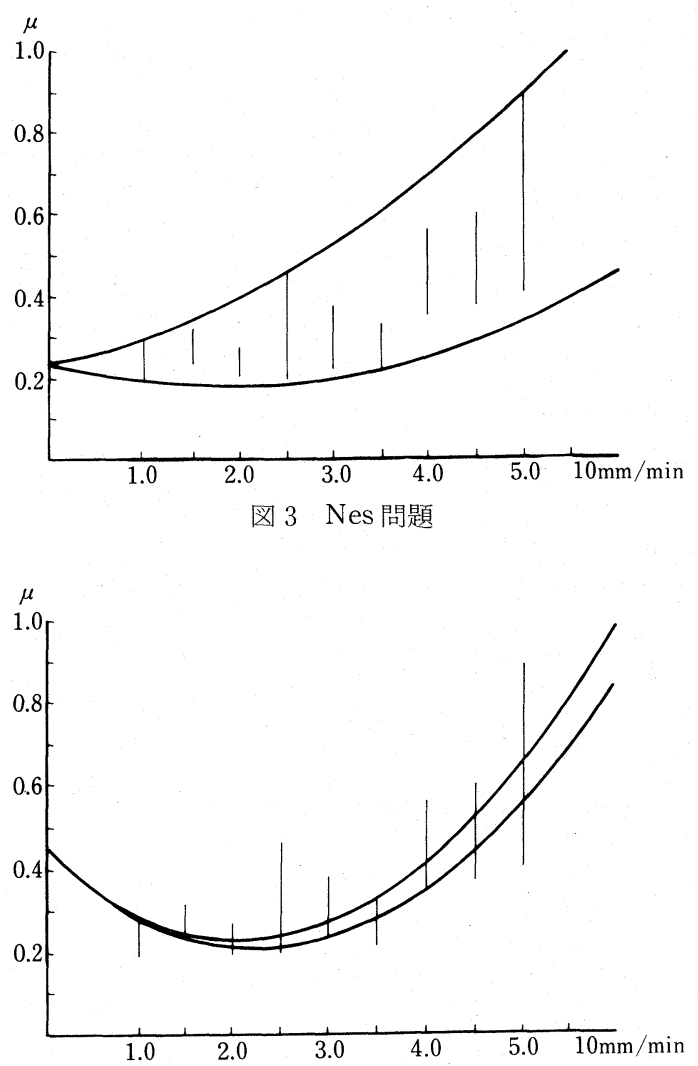

図 4 C-Nes 問題

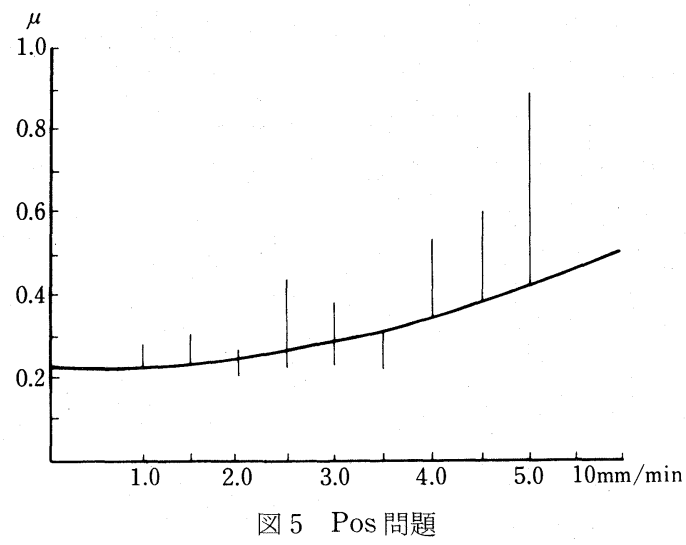


として, 三つの定式化によって次のような解を得た。

Nes 問題 $\quad: \bar{A}_{0}=(0.236,0)$,

$\bar{A}_{1}=(-0.007,0.055)$

$\bar{A}_{2}=(0.016,0)$

C-Nes 問題 : $\underline{A}_{0}=(0.477,0)$,

$$
\underline{A}_{1}=(-0.206,0)
$$$$
\underline{A}_{2}=(0.047,0.002)
$$

Pos 問題 $\quad: \widehat{\widehat{A}}_{0}=(0.222,0)$,

$\widehat{A_{1}}=(0,0)$

$\bar{A}_{2}=(0.008,0)$

図3 図 5 に Nes, C-Nes, Pos 問題によるそれぞれ の推定区間を示す.Pos 問題に㧈いて $\hat{J}(\widehat{\boldsymbol{c}})=0$ である ので, C-Nes 問題の解が存在する.

\section{6. 終わりに}

出力データを区間として考光るのは, 出力データの 持っている不確定性を考慮すためである。この出力 データの巾は部分的無知量を表わして扣り，それを反 映した区間線形モデルで現象のあいまいさを表わして いる。応用例 5.2 で取扱ったように実験の繰り返しか ら区間出力データを得ることができる。さらにもっと 一般的に専門家の推定を取扱らょうな場合は，区間線 形回帰モデルの応用は広く考壳られる。亦た推定され る係数の範囲を専門家から得た知識によって拘束する ことが容易にできるので，推定された区間線形回帰モ デルが我々の直感に近いものになると考光られる。

\section{参 考 文 献}

Dubois, D. and Prade, H. (1980) Fuzzy Sets and Systems: Theory and Application, Academic Press, New York.

Heshmaty, B. and Kandel, A. (1985) Fuzzy linear regression and its applications to forecasting in uncertain environment, Int. J. of Fuzzy Sets and Systems 15, 159-191.

Hayashi, I. and Tanaka, H. (1987) The fuzzy GMDH algorithm by possibility models, Preprints of 2nd Int. Fuzzy Systems Assocaiton Congress July 20-25, Tokyo, 1, 321-324.

Pawlak, Z. (1982) Rough sets, Int. J. of Computer and Information Sciences, 11, 5, 341-356.

Tanaka, H., Uejima, S. and Asai, K. (1982) Linear regression analysis with fuzzy model, IEEE Trans. Systems, Man, and Cybernetics, SMC12-6, 903-907.

田中英夫 (1984) 可能性モデルとその応用，システム と制御， 28，7，447-451.

田中英夫, 林 勲, 和多田淳三(1986) ファジイ線 形回帰分析の三つの定式化, 計測自動制御学会論 文集，22，10，45-51.

Tanaka, H., Hayashi, I. and Watada, J. (1987) Possibilistic linear regression analysis based on possibility measure, Preprints of 2nd Int. Fuzzy Systems Association Congress, July 2025, Tokyo, 1, 317-320.

Tanaka, H. (1987) Fuzzy data analysis by possibilistic linear models, Int. J. of Fuzzy Sets and Systems, 24, 363-375.

Zheng, C.B. (1982) On application of fuzzy linear regression models, Working Paper of Technical Institute of Ming Tsi, Taiwan. 